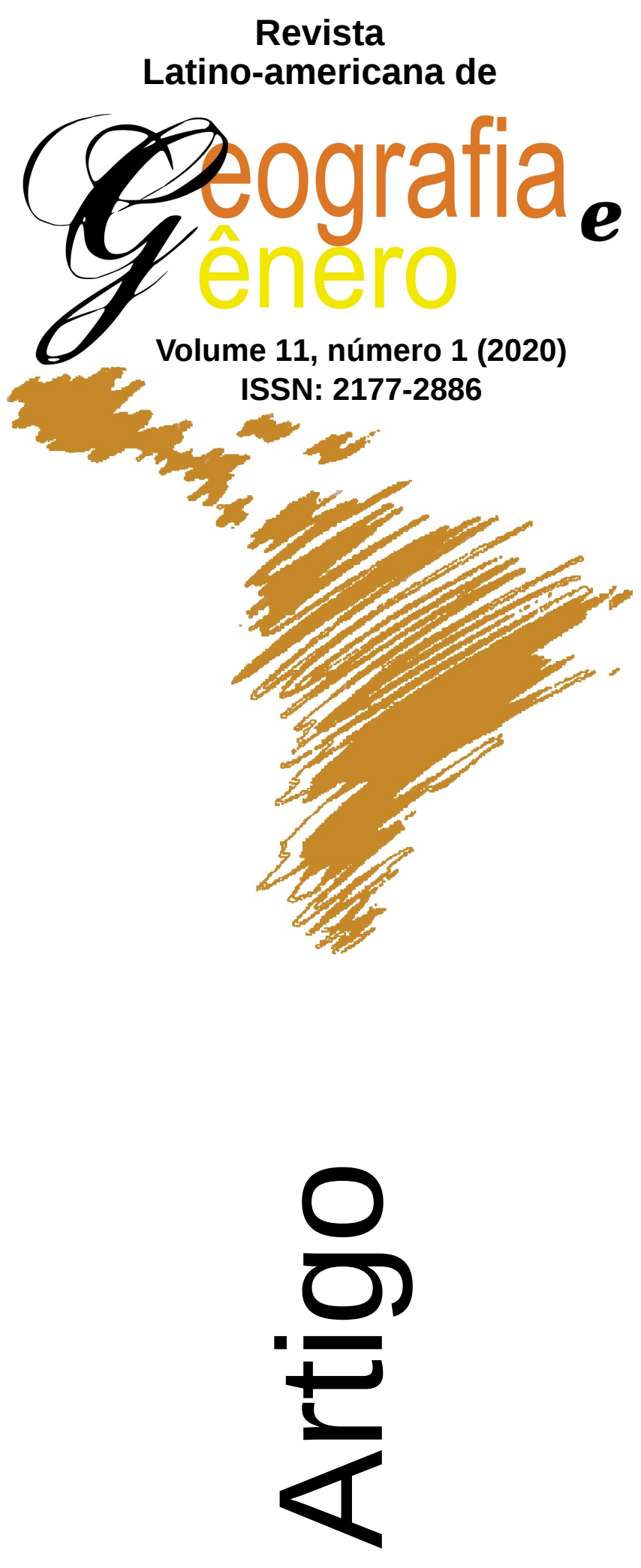

\title{
Mulher, Professora e \\ Pesquisadora: Trajetórias \\ Socioespaciais de Docentes \\ Efetivas da Universidade Federal do Tocantins - Campus Araguaína
}

Mujeres, Profesoras e Investigadoras: Trayectorias Socio-Espaciales de Docentes Efectivas en la Universidad Federal de Tocantinas - Campus Araguaína

Woman, Teacher and Researcher: Socio-Spatial Trajectories of Full Professor Women in the Federal University of Tocantins - Campus Araguaína

\author{
Raquel Almeida Mendes \\ Universidade Federal de Goiás \\ almeidamendesraquel@gmail.com \\ Kenia Gonçalves Costa \\ Universidade Federal do Tocantins \\ keniacost@uft.edu.br
}

Como citar este artigo:

MENDES, Raquel Almeida; COSTA, Kenia Gonçalves. Mulher, Professora e Pesquisadora: Trajetórias Socioespaciais de Docentes Efetivas da Universidade Federal do Tocantins - Campus Araguaína. Revista Latino Americana de Geografia e Gênero, v. 11, n. 1, p. 152 - 171, 2020. ISSN 21772886.

Disponível em:

http://www.revistas2.uepg.br/index.php/rlagg 


\title{
Mulher, Professora e Pesquisadora: Trajetórias Socioespaciais de Docentes Efetivas da Universidade Federal do Tocantins - Campus Araguaína
}

\author{
Mujeres, Profesoras e Investigadoras: Trayectorias Socio-Espaciales de \\ Docentes Efectivas en la Universidad Federal de Tocantinas - Campus \\ Araguaína
}

\section{Woman, Teacher and Researcher: Socio-Spatial Trajectories of Full Professor Women in the Federal University of Tocantins - Campus Araguaína \\ Resumo}

A presente pesquisa discute as trajetórias socioespaciais das docentes efetivas do campus universitário da UFT em Araguaína - TO. O procedimento metodológico adotado consiste na análise dos currículos científicos e realização de entrevistas semiestruturadas com docentes da unidade Cimba e EMVZ. Por meio dos currículos científicos e das oralidades tornou-se possível averiguar os trajetos acadêmicos das professoras e as implicações das hierarquias de gênero estabelecidas no âmbito científico. Notamos que a ciência ainda reflete um campo masculinizado em função da construção social e histórica das representações femininas atreladas ao meio privado/doméstico, corroborando para uma persistência das relações de dominação patriarcais.

Palavras-Chave: Professoras; UFT; Trajetórias Socioespaciais; Gênero.

\section{Resumen}

La presente investigación discute las trayectorias socioespaciales de las docentes efectivas del campus universitario de UFT en Araguaína - TO. El procedimiento metodológico adoptado consiste en analizar los planes de estudio científicos y realizar entrevistas semiestructuradas con profesoras de las unidades Cimba y EMVZ. A través de los currículums científicos y la oralidad, se hizo posible determinar las trayectorias académicas de las docentes y las implicaciones de las jerarquías de género establecidas en la esfera científica. Observamos que la ciencia aún refleja un campo masculinizado debido a la construcción social e histórica de las representaciones femeninas vinculadas al entorno privado / doméstico, corroborando la persistencia de las relaciones de dominación patriarcal.

Palabras-Clave: Docentes; UFT; Trayectorias Socioespaciales; Género.

\section{Abstract}

The present research discusses the socio-spatial trajectories of the full professor women of the UFT university campus in Araguaína (TO). The methodological procedure adopted consisted of the analysis of scientific curriculum and semi-structured interviews with woman teachers from Cimba and EMVZ units. Through scientific curriculum and oralities it was possible to verify the academic paths followed by those teachers and the implications of the gender hierarchies established in the scientific scope. We noted that science still shows up as a masculinized field due to the social and historical construction of female representations as linked to the private/domestic environment, that reinforces the persistence of patriarchal relations of domination.

Keywords: Full Professor Women; UFT; Socio-spatial Trajectories; Gender. 


\section{Introdução}

O presente artigo pretende discutir sobre o lugar da mulher no meio científico, a partir de um estudo sobre as trajetórias socioespaciais de docentes na Universidade Federal do Tocantins - campus Araguaína e visando entender em quais medidas as desigualdades de gênero e o sexismo constituem os trajetos acadêmicos femininos.

A Universidade Federal do Tocantins (UFT), recorte espacial desta pesquisa, foi implantada no ano de 2003 e atualmente apresenta um quadro de 57 cursos de graduação, 30 programas de pós-graduação e mais de 20 mil discentes distribuídos em 7 campi universitários localizados nos municípios de Palmas, Araguaína, Gurupi, Miracema, Tocantinópolis, Porto Nacional e Arraias.

A UFT é uma instituição de extrema importância para a população tocantinense, tendo em vista a ampliação da oportunidade de acesso ao ensino superior, a formação de profissionais qualificados e a difusão de saberes nas mais diversas instâncias, fornecendo oportunidades de formação no campo das Ciências Sociais Aplicadas, Humanas, Educação, Agrárias, Tecnológicas, Engenharias, Ciências Biológicas e da Saúde.

Tendo em vista a relevância da Universidade Federal do Tocantins para produção científica tocantinense, surge o interesse por pesquisar sobre as cientistas presentes nesta instituição e suas contribuições para a ciência, priorizando, sobretudo as mulheres cientistas.

Mapa 01: Localização das unidades Cimba e EMVZ do campus universitário de Araguaína
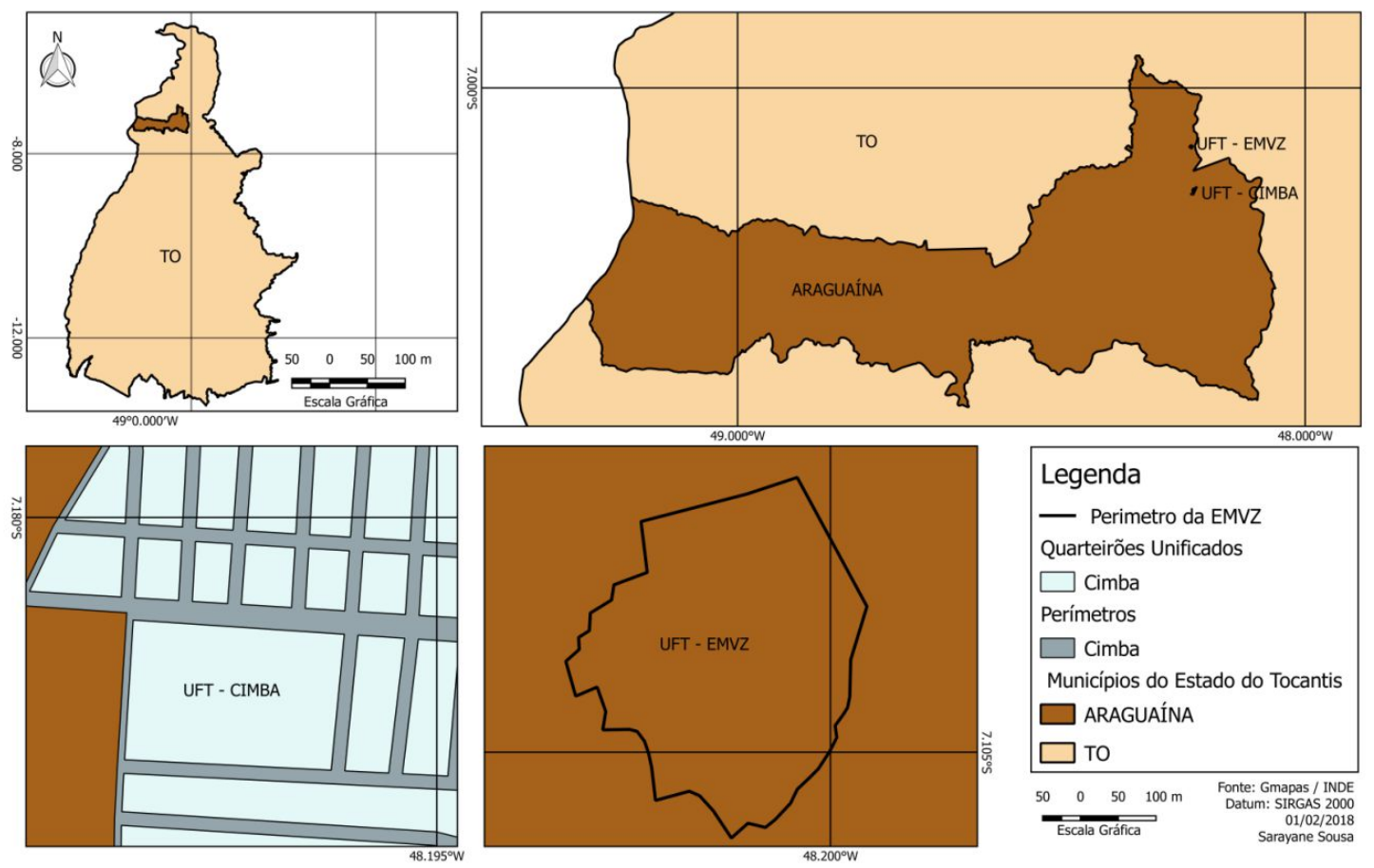

Fonte: Gmapas/INDE. Elaboração: SOUSA, 2018.

O propósito do presente trabalho é visibilizar e investigar as mulheres cientistas da UFT campus Araguaína (Mapa 01) a partir de uma análise sobre suas trajetórias socioespaciais, suas vivências no meio acadêmico e as 
dificuldades de estarem inseridas em áreas estruturalmente e historicamente masculinas.

A compreensão dos trajetos e vivências das interlocutoras ocorrerá a partir da discussão de Cirqueira (2010) sobre trajetórias socioespaciais, que segundo o autor remete às historiografias e as bagagens simbólicas de cada indivíduo, interligadas as temporalidades e espacialidades que se configuram de forma descontínua e não linear, sendo de grande importância na medida em que as experiências não acontecem de forma aleatória, mas são demarcadas por momentos e lugares que se tornam referências simbólicas aos indivíduos.

A busca pela compreensão da realidade por meio das lentes geográficas ocorre pela chave da análise espacial, da relação sociedade-natureza e do entendimento de categorias tais como lugar, território, região e paisagem (GIOMETTI, PITTON, ORTIGOZI, 2012) que cerceada por vertentes tradicionais tende a entender os sujeitos inseridos no espaço como universais.

As novas perspectivas da Geografia cultural, buscando romper com paradigmas genéricos, trazem a ideia de que o entendimento de fenômenos sociais pela ótica do espaço deve abranger os marcadores da diferença, entrando nesse caso o debate geográfico das questões de gênero.

A ausência das discussões sobre gênero constituem um fazer geográfico cada vez mais simplista e universalizante no tocante a realidade dos sujeitos sociais que, sem considerar as nuances generificadas, bem como outras categorias tais como raça e etnia, reafirma o caráter hegemônico e hierárquico da ciência (REIS, 2015).

Luciane Lopes (2015) endossa que:

Os estudos sobre gênero se enquadram na geografia justamente pelo fato de essas formas de relações estarem presentes na dinâmica de produção do espaço a partir das relações sociais, que se modificam constantemente e interferem na configuração socioespacial a que pertencem (LOPES, 2015, p. 157).

Sendo assim, considerar as espacialidades perpassadas pelo caráter social das relações de gênero tem fomentado pesquisas geográficas capazes de construir saberes e métodos contra-hegemônicos, visando a não subalternização de determinados grupos e a maior visibilidade dos debates sobre a diferença.

Não podendo negar as potencialidades da Geografia nos estudos sobre gênero, a pesquisadora Joseli Maria Silva (2010) discute que o silenciamento perante as questões supracitadas tem mais a dialogar com as relações de poder contidas no campo da ciência, do que uma suposta incompatibilidade ao objeto de conhecimento geográfico.

Partindo para o delineamento metodológico da pesquisa, foi tomado como ponto inicial a construção do referencial teóricolbibliográfico, com direcionamento principal aos estudos sobre gênero, feminismo, trajetórias socioespaciais, dentre outros.

As questões norteadoras da pesquisa concentram-se em três principais: Em que medida as desigualdades de gênero se fizeram presentes nas trajetórias socioespaciais das docentes? A academia se apresenta como um ambiente 


\begin{abstract}
hostil as mulheres cientistas? Como as trajetórias socioespaciais são regidas considerando o aspecto patriarcal que estrutura a sociedade científica?

Foram adotadas abordagens qualiquantitativas, fundamentadas nos trabalhos de Ramires e Pessôa (2009). A obtenção de dados sobre o corpo docente feminino ocorreu por meio de solicitação ao setor de recursos humanos da universidade. $\mathrm{O}$ acesso a dados tais como nome, naturalidade, área de atuação e currículo acadêmico, possibilitou-nos, desse modo, uma caracterização inicial das trajetórias.

A primeira etapa da pesquisa é concluída com a sistematização das trajetórias acadêmicas. Foram tomados como base a análise dos currículos científicos presentes na plataforma Lattes e a partir de então o reconhecimento do percurso feito desde a graduação até a última titulação conclusa.

A segunda etapa da pesquisa consiste na realização de entrevistas semiestruturadas. $\mathrm{O}$ roteiro de perguntas, alinhado ao viés fenomenológico (TRIVIÑOS, 1987), visava abordar as subjetividades e vivências acadêmicas das interlocutoras que somente o viés da oralidade poderia evidenciar. Considerou-se a amostragem de 13 docentes na etapa das entrevistas, uma docente por cada curso em funcionamento no campus universitário, critério estipulado pelas autoras a fim de compreender as singularidades das experiências femininas, segundo cada área da ciência.

O presente trabalho está dividido em duas seções. A primeira consiste em apontamentos sobre os primórdios das pesquisas no campo das relações de gênero, do debate sobre as mulheres na ciência e do próprio movimento feminista, enquanto que a segunda parte discute diretamente as trajetórias socioespaciais das docentes e suas narrativas quanto mulheres pesquisadoras.
\end{abstract}

\title{
Gênero, Feminismo e Mulheres na Ciência: Alguns apontamentos
}

O movimento feminista tem apresentado como uma de suas principais pautas a busca por discutir e lutar contra a invisibilidade da mulher em diversos contextos, inclusive no contexto científico.

Considerando a sociedade patriarcal que vivemos, há uma resistência no que concerne a inserção das mulheres no mundo científico. A função social feminina, construída tempos a fio, esteve destinada de forma massiva ao âmbito da maternidade e/ou dos afazeres domésticos, impedindo que as mulheres não pudessem exercer atividades destoantes dos papéis de gênero preestabelecidos (SCHIEBINGER, 2001).

O movimento feminista surge com o objetivo de quebrar noções preconcebidas sobre a vida e corpo das mulheres, tendo em vista que anteriormente as mulheres pouco podiam optar pelos seus trajetos, sequer era permitido que as mulheres frequentassem ambientes para além da esfera privada/doméstica.

Alves e Pitanguy, na obra 'O que é feminismo?' discorre que:

O movimento feminista denuncia a manipulação do corpo da mulher e a violência a que é submetido, tanto aquela que se atualiza na agressão física - espancamentos, estupros, assassinatos - quanto a que o coisifica como objeto de consumo. Denuncia da mesma forma a 
violência simbólica que faz de seu sexo um objeto desvalorizado. Reivindica, também, o direito à informação e ao acesso a métodos contraceptivos seguros, masculinos e femininos. Propõe, principalmente que o exercício da sexualidade se desvincule da função biológica de reprodução, exigindo dessa forma o direito ao prazer sexual e à livre opção pela maternidade. Neste sentido, advoga o aborto livre, e a ruptura com os moldes tradicionais em que o desempenho sexual da mulher vem sendo encerrado (ALVES e PITANGUY, 1985, p. 60).

No que concerne as mulheres e o acesso à educação, havia poucas possibilidades, sendo assim, “[...] nesse período, poucas mulheres estudaram e lecionaram em universidades, somente a partir do século XIII, primeiramente na Itália [...] (SILVA, 2012, p. 18)". O meio acadêmico passou a ser frequentado por mulheres depois de muito empenho e quebras de paradigmas, "[...] as universidades, embora tenham sido criadas no século XII, só passaram a admitir efetivamente as mulheres em seu quadro de discentes e docentes no final do século XIX e início do século XX [...]” (SCHIEBINGER, 2001, p. 18).

Apesar de toda a exclusão no contexto científico, mulheres cientistas, ainda que pouco numerosas, se mantiveram presentes. Mesmo perante uma ciência estruturada em bases masculinas e com produções científicas pouco reconhecidas, elas ainda conseguiram deixar um legado estimulador na história da ciência (SILVA, 2012).

A representação da mulher na história científica é narrada de forma ínfima e desprovida de protagonismos. Segundo Ana Colling em sua obra intitulada "A construção histórica do feminino e do masculino" (2004):

[...] desde que a História existe como disciplina científica, ou seja, desde o século XIX, o seu lugar dependeu das representações dos homens, que foram, por muito tempo, os únicos historiadores. Estes escreveram a história dos homens, apresentada como universal, e a história das mulheres desenvolveu-se à sua margem. Ao descreverem as mulheres, serem seus porta-vozes, os historiadores ocultaram-nas como sujeitos, tornaram-nas invisíveis. Responsáveis pelas construções conceituais hierarquizaram a história, com os dois sexos assumindo valores diferentes; o masculino aparecendo sempre como superior ao feminino (COLLING, 2004, p. 13).

Dessa forma, para entendermos o processo de hierarquização, iniciaremos abordando o conceito de gênero, as representações do masculino e feminino, dentre outros conceitos adjacentes tais como sexo e sexualidade.

Segundo Alves e Pitanguy (1985), o termo 'Gênero' pode ser descrito como algo construído socialmente e culturalmente, sendo um dos principais motivos pelo qual são atribuídas diferentes funções para homens e mulheres na sociedade, de acordo com aspectos políticos, costumes, cotidiano e fenômenos de cada lugar.

Para Guacira Louro (1997), o termo 'Gênero' surge para romper os laços 
estritamente biológicos no que tange as distinções sociais existentes entre feminilidades e masculinidades, e passa a ser compreendido como um conceito fundamental para o feminismo.

A teórica sobre questões de gênero, Judith Butler, evidencia que "[...] por mais que o sexo pareça intratável em termos biológicos, o gênero é culturalmente construído: consequentemente, não é nem o resultado causal do sexo nem tampouco tão aparentemente fixa quanto o sexo [...]" (BUTLER, 1990, p. 15).

O advento do conceito 'Gênero' fomenta o debate no campo social, haja vista que é neste contexto que os gêneros são construídos, trazendo a relevância de discutir o contexto patriarcal que estrutura a sociedade e os aspectos relacionais entre mulheres e homens na cotidianidade.

Sendo assim, o patriarcado é a hierarquia existente e implantada no seio social entre homens e mulheres. A dominação masculina surge a partir do aparato social de subjugação feminina, no qual mulheres, em todas as áreas de convivência humana, são situadas abaixo do poderio masculino, acarretando uma série de violências e opressões históricas (SAFFIOTI, 2004).

A sociedade patriarcal cristaliza as desigualdades de gênero, confina mulheres a vida privada e dessa forma nós nascemos e crescemos condicionadas a corresponder ao patriarcado, a partir de uma vida a margem, cheia de vetos e imposições sociais de gênero.

A representação social do que seria masculino e feminino contribui para a manutenção do ideário de mulher não pertencente ao meio científico. De acordo com Branca Alves e Jacqueline Pitanguy:

O "masculino" e o "feminino" são criações culturais e, como tal, são comportamentos apreendidos através do processo de socialização que condiciona diferentemente os sexos para cumprirem funções sociais específicas e diversas. Essa aprendizagem é um processo social. Aprendemos a ser homens e mulheres e a aceitar como "naturais" as relações de poder entre os sexos (ALVES e PITANGUY, 1985, p. 55).

No âmbito dos estudos sobre gênero é de extrema relevância discorrer sobre os conceitos de público e privado, conceito que se relaciona estreitamente com as concepções de 'feminino' e 'masculino', haja vista que há correspondências de gênero perante essas esferas. $\mathrm{O}$ conceito de público e privado é discutido por Susan Okin, a mesma destaca que:

[...]"o privado" sendo usado para referir-se a uma esfera ou esferas da vida social nas quais a intrusão ou interferência em relação à liberdade requer justificativa especial, e "o público" para referir-se a uma esfera ou esferas vistas como geralmente ou justificadamente mais acessíveis (OKIN, 2008, p. 305).

A dicotomia 'público' e 'privado' é muito significante para os estudos sobre gênero, principalmente na insistência de estudiosas feministas em discutir que 'o pessoal é político', e que não dá pra desassociar tais discussões. Na verdade, foi pela falta de correlação entre as esferas que se constituiu diante das 
relações familiares um caráter a-histórico e apolítico, como destaca Susan Okin:

O que, então, outras feministas, assim como as mais radicais, querem dizer com 'o pessoal é político'? Nós queremos dizer, primeiramente, que o que acontece na vida pessoal, particularmente nas relações entre os sexos, não é imune em relação à dinâmica de poder, que tem tipicamente sido vista como a face distintiva do político. E nós também queremos dizer que nem o domínio da vida doméstica, pessoal, nem aquele da vida não-doméstica, econômica e política, podem ser interpretados/isolados um do outro (OKIN, 2008, p. 314).

A dicotomia público/privado representa uma das raízes históricas de opressão feminina. A mulher é estereotipada como alguém 'naturalmente' ligada ao ambiente doméstico, aos cuidados com o lar e criação dos filhos, enquanto o homem é responsabilizado por trabalhar e manter o lar, provendo o sustento e exercendo o poderio político de 'chefe do lar'.

$\mathrm{O}$ processo hierárquico estabelecido entre homens e mulheres e refletido nos mais diversos meios, inclusive na ciência, fez com que o público masculino tivesse acesso antecipado e privilegiado ao fazer científico. Diferentemente das mulheres, que condicionadas à esfera privada, tiveram o direito de adentrar as universidades posteriormente, o que consequentemente acarretou numa participação tardia das mulheres na produção científica.

O imaginário social ainda desenha o cientista como sendo alguém do gênero masculino, além de outros atenuantes tais como branco, cisgênero e heterossexual. Cabe frisar que mesmo com o aumento significativo do número de mulheres na ciência, elas ainda são subalternizadas e suas produções científicas ainda vistas como pouco relevantes.

\section{Trajetos femininos e desigualdades de gênero: oralidades de pesquisadoras/docentes do campus universitário de Araguaína}

A Universidade Federal do Tocantins (campus Araguaína) apresenta na atualidade um quadro docente feminino de 104 professoras, sendo 05 especialistas, 33 mestres e 66 doutoras (UFT-GDH, 2017), o que nos aponta um quadro docente bastante qualificado. Uma grande parcela das docentes ainda se mantém em processo de qualificação, algo constatado em seus currículos na Plataforma Lattes (CNPq, 2018).

Uma característica percebida na pesquisa foi a de um quadro docente feminino que, em sua grande maioria, não advém da cidade de Araguaína e região. Trata-se então de mulheres com trajetórias acadêmicas extensas, em diversas instituições e regiões do país.

Consideramos importante citar que no universo de 106 professoras, apenas 6 são araguainenses ou das proximidades de Araguaína. A presença de poucas docentes com formação pela UFT ou demais universidades tocantinenses, fez necessária a presença de profissionais de diferentes regiões brasileiras (MAPA 02 ), até mesmo advindas de fora do país. 


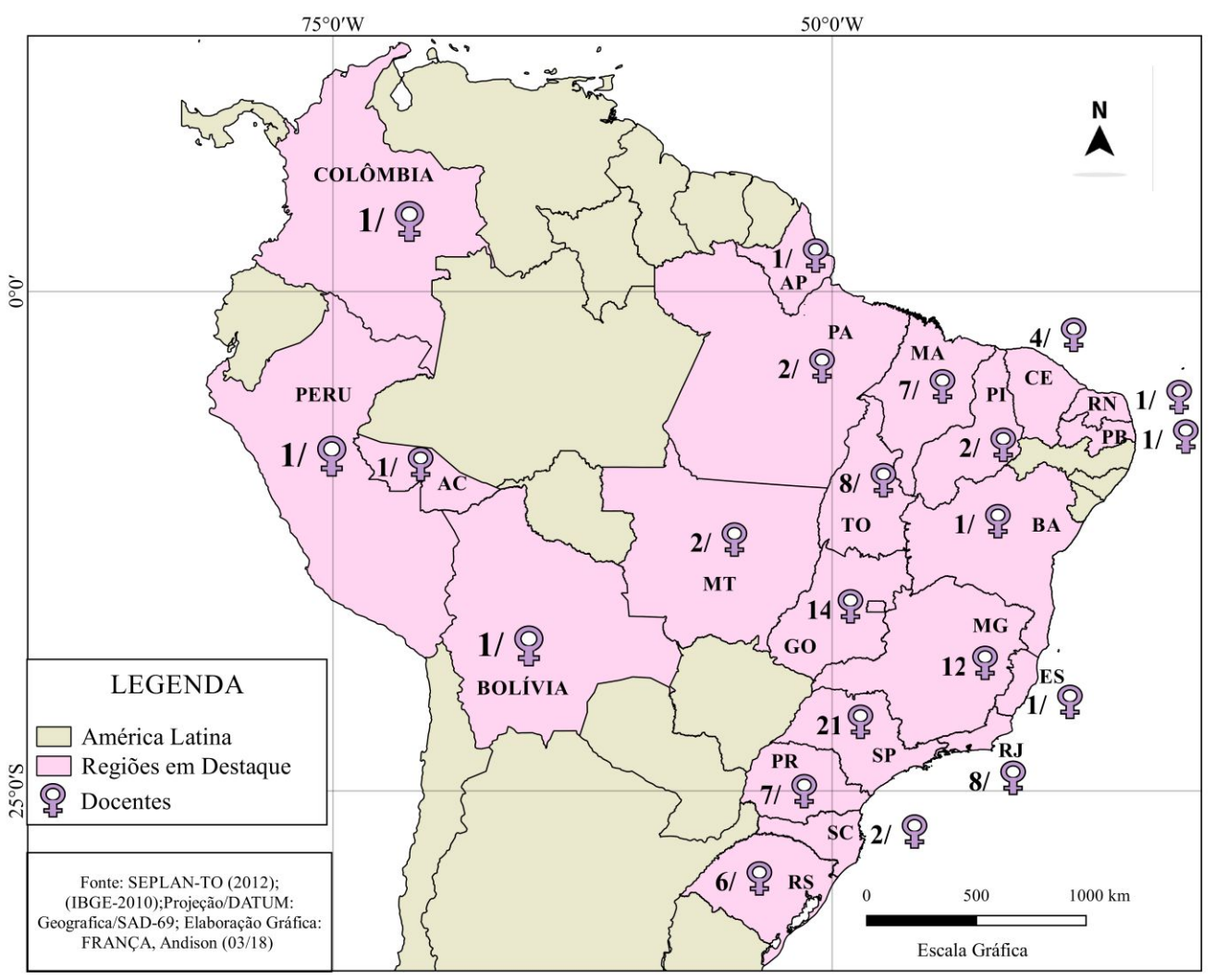

Fonte: UFT-GDH, 2017; CNPQ, 2018; Dados primários: MENDES, 2018; Elaboração: FRANÇA, 2018.

As trajetórias socioespaciais, segundo a oralidade das docentes, foram marcadas pelo sexismo e misoginia. Os trajetos longínquos das docentes denotam, de modo geral, uma formação docente bastante especializada, ou seja, mulheres que percorreram diversos espaços em prol de seus processos formativos. Para além dos percalços próprios a vida universitária, a mulher se depara com outras questões próprias a construção social dos gêneros e da condição patriarcal que vivemos, acarretando em inúmeros obstáculos ao lugar feminino no âmbito acadêmico-científico.

O processo de obtenção das informações sobre as trajetórias socioespaciais das docentes da UFT ocorreu tomando como base a análise dos currículos científicos localizado na Plataforma Lattes (CNPq, 2018), onde consta o percurso acadêmico, desde a graduação até a conclusão da pesquisa, bem como as formações em andamento. A Gerência de Desenvolvimento Humano da UFT, campus Araguaína, também contribuiu com o fornecimento de dados quanto à naturalidade (Mapa 02), escolaridade, etnia, dentre outras características do quadro docente feminino.

As entrevistas semiestruturadas foram de grande valia na compreensão das desigualdades de gênero, sendo possível aferir em que medida se fizeram presentes nas trajetórias socioespaciais de cada interlocutora, bem como as subjetividades de cada percurso espacial.

Não obstante, é notório destacar o papel da ciência Geográfica na compreensão das relações entre natureza teórica, física e, sobretudo social. $\mathrm{O}$ 
ser humano, como fator determinante na construção do espaço geográfico, utiliza-se de técnicas para transformações do meio e, na medida que produz o espaço, estabelece elos de identidade e pertencimento ao Lugar. Os sujeitos ao transformarem o espaço natural (geográfico) em espaço social constituem relações políticas, econômicas, étnico-raciais, culturais e de poder, entrando também o viés das relações de poder entre os gêneros, dentre outras temáticas de suma importância na inter-relação sociedade e natureza, ser humano e meio.

Dessa forma, discutimos sobre conhecimento socioespacial e as relações estabelecidas na produção e organização do espaço, tendo em vista que o conceito-chave não é apenas um mero palco de acontecimentos, mas um relação contínua e viva dos sujeitos inseridos (SANTOS, 1997). As trajetórias podem ser entendidas a partir do viés de análise espacial, sobretudo na Geografia, quando ao manter diálogo com outras ciências, consegue destrinchar sobre as nuances simbólicas presentes em cada espacialidade. Neste caso, sobre as relações de gênero e as hierarquias sociais e históricas que contribuíram para uma sociedade o homem adentra aos espaços com liberdade e autonomia enquanto as mulheres percorrem com ressalvas.

A articulação de grupos em prol da conquista de direitos femininos, LGBT's e da população negra, dentre outros, a partir da década de 1970, gerou mudanças nos campos políticos de atuação, algo que incidiu diretamente em novos questionamentos no âmbito acadêmico. As ciências humanas e sociais, tais como a Antropologia e a História passaram a inserir o debate da diferença como relevante em suas perspectivas teóricas, todavia a Geografia, de forma comparativa a outras ciências, ainda apresenta debates acanhados (VELEDA DA SILVA, 2009).

Adentrando diretamente ao campo de estudos sobre gênero na ciência geográfica, denominada geografia do gênero, entende-se que:

Têm como foco principal analisar as relações existentes entre espaço e gênero, determinando papéis e funções dos gêneros, a divisão do trabalho e as relações de poder entre eles. As relações de gênero [...] fazem referência às relações de poder existentes entre homens e mulheres; geralmente, em âmbitos espaciais, culturais e temporais existe uma relação de subordinação das mulheres com relação aos homens, o que incita a ciência a fazer reflexões consistentes sobre a visão de mundo sexista (SOUZA, 2007, p. 48).

Cabe frisar que há uma persistente invisibilidade no que tange as discussões sobre gênero na Geografia, causada, por vezes, pela visão tradicionalista, eurocentrada e estruturalmente masculinizada. Ao debater sobre as invisibilidades, Joseli Silva salienta que:

[...]a geografia brasileira, apesar de avançar no sentido de tornar importante a concepção da relação entre o "ser que age" e o espaço, apresenta, em sua estrutura curricular, agentes, sujeitos e atores genéricos ou universais. A humanidade, na perspectiva da geografia brasileira, continua sendo tratada, na maior parte das vezes, apenas como polarizada entre capitalistas e trabalhadores. [...] gerando um 
Mulher, Professora e Pesquisadora: Trajetórias Socioespaciais de Docentes

Efetivas da Universidade Federal do Tocantins - Campus Araguaína

discurso que encobre interesses e identidades que são escamoteadas pelas simplificadoras máscaras institucionais. Adotar a perspectiva de gênero na geografia brasileira significa romper com tais generalizações e partir para análises centradas na pluralidade dos seres humanos [...] (SILVA, 2009, p. 58).

A ciência geográfica, além de trazer o debate do campo de gênero e dos saberes socioespaciais na pesquisa em questão, também contribuiu a partir de instrumentos cartográficos, a materialização das relações entre interlocutoras e meio. Dessa forma, a produção de mapas nos apresenta muito mais que meras localizações no plano cartesiano, ou seja, nos permite espacializar os trajetos e elencar questões discutidas no viés das oralidades.

Mapa 03. Trajetórias acadêmicas das interlocutoras entrevistadas

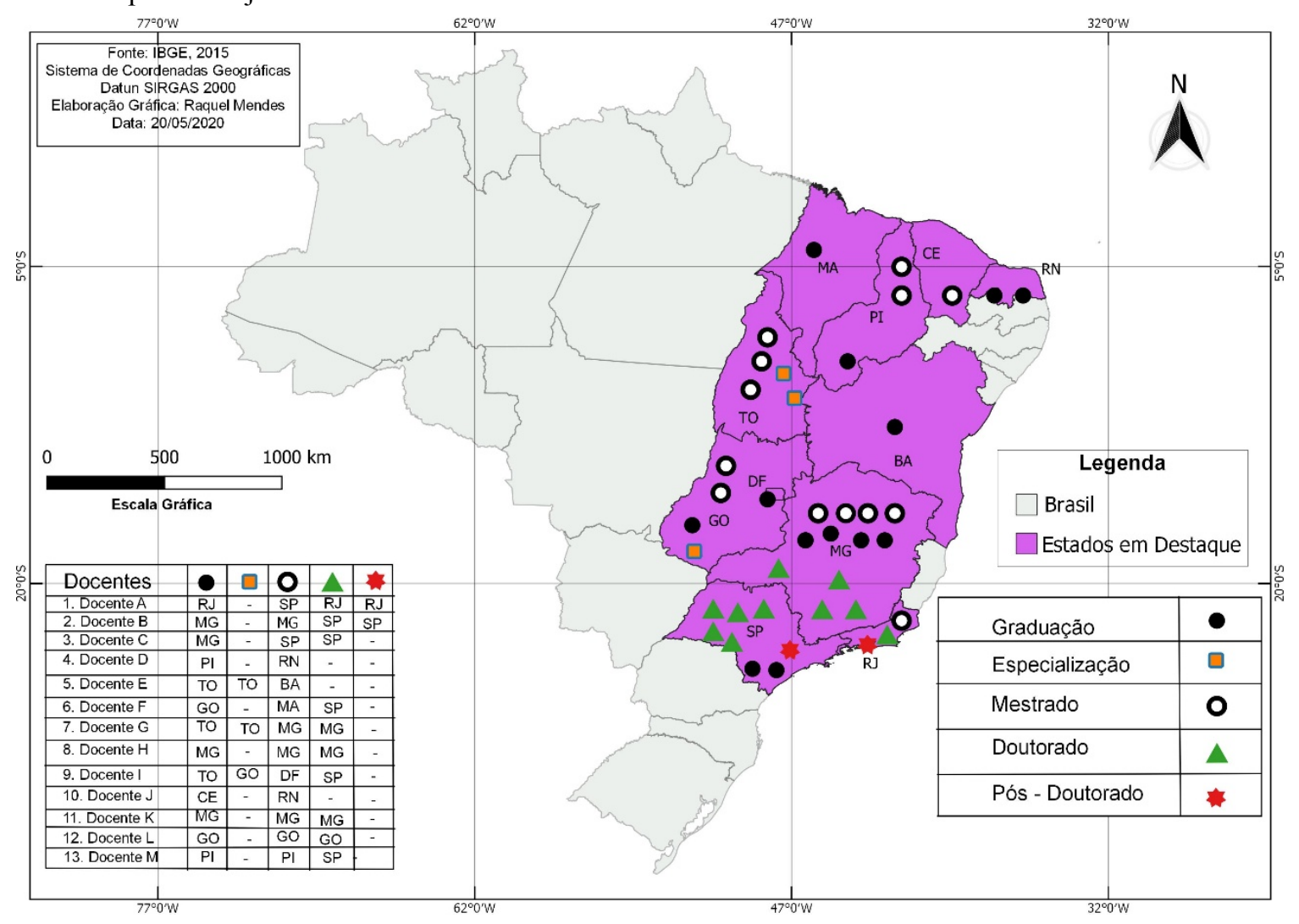

Fonte: UFT/ GDH - Araguaína; CNPQ, 2018; Dados primários: MENDES, 2018; Elaboração: MENDES, 2020.

Em cada entrevista realizada, em cada diálogo com as interlocutoras, tornou-se perceptível os empecilhos de uma sociedade sexista perante as trajetórias acadêmicas das professoras. Ainda que o processo de superação tenha sua urgência, o que está sendo discutido aqui não é unicamente o fortalecimento das mulheres para fins de transpor as barreiras do machismo, mesmo sendo de extrema relevância. Propõe-se uma reflexão no que tange a necessidade de mudanças estruturais e institucionais.

Discutir sobre trajetórias socioespaciais é, sobretudo reconhecer que os trajetos percorridos são influenciados por inúmeras questões do campo social, inerentes aos sujeitos. Sendo assim, cabe entender que o espaço não se 
comporta como um mero palco de acontecimentos sociais, onde ações ocorrem passivamente, " $[\ldots]$ cremos que o espaço, da mesma forma que a sociedade, influenciam as trajetórias. Ou seja, as trajetórias possuem uma dimensão socioespacial" (CIRQUEIRA, 2010, p. 43). de:

Reiterando sobre a categoria espaço, de acordo com Milton Santos trata-se

Um conjunto indissociável de que participam de um lado, certo arranjo de objetos geográficos, objetos naturais e objetos sociais, e, de outro, a vida que os preenche e os anima, ou seja, a sociedade em movimento [...] O espaço por conseguinte é isto: um conjunto de formas contendo cada qual frações da sociedade em movimento. As formas, pois, tem um papel na realização social (SANTOS, 1997, p. 26).

O conceito de espacialidade, dessa maneira, necessita ser evidenciado como um dado resultante das interações entre homem/mulher com o espaço, onde são designados os elementos subjetivos e imateriais do processo interativo. Cabe frisar que "[...] a espacialidade como linguagem do espaço, possui uma escala, uma dimensão temporal, uma função específica e uma localidade" (CIRQUEIRA, 2010, p. 31).

As inferências das questões sociais no espaço e vice-versa, representa a perspectiva do conceito de trajetórias socioespaciais abordado no trabalho. A história dos indivíduos e as experiências dentro de cada percurso, não são aleatórias, sequer resultantes do acaso, se encontram dentro de uma espacialidade e temporalidade.

Para uma melhor compreensão das trajetórias socioespaciais:

[...] deve se construir os estados sucessivos do campo dentro qual elas se desenrolam, os vários lugares e experiências pelas quais o indivíduo perpassa, unindo um ator social a outros cujas vivências se desenvolvem no mesmo campo e no mesmo conjunto de possibilidades (CIRQUEIRA, 2010, p. 44).

As implicações do 'ser mulher' são inúmeras, a identidade feminina é marcada por perfis pré-fabricados dotados de hierarquia de gênero e opressões variadas. Tecer considerações sobre desigualdades de gênero por vezes é uma tarefa desconfortável, além de ser visualizada como uma temática desnecessária, pode ser lida como radicalismos e misandria (desprezo e rejeição a figura masculina), uma concepção errônea haja vista que há, sobretudo, uma busca pela equidade, não uma mera sobreposição de gêneros.

Pesquisas como esta apontam privilégios e situações recorrentes na estrutura patriarcal, onde são questionadas e colocadas mudanças necessárias para uma sociedade mais equitativa. $\mathrm{O}$ avanço das perspectivas feministas e dos estudos sobre gênero tem resultado em mulheres que não se submetem mais a inúmeros condicionamentos machistas, pelo contrário, estas questionam e tentam construir relações mais equânimes.

De acordo com a revisão bibliográfica para a feitura deste trabalho:

Raquel Almeida Mendes, Kenia Gonçalves Costa 
Os atores sociais seguem trajetórias nas quais vão configurando suas relações com outros atores, a sua própria maneira de perceber a realidade e de vivê-la, construindo sua própria identidade e, muitas vezes, constituindo territórios e lugares. No entanto, alguns atores sociais são repelidos a territórios já demarcados para e por uma dita sociedade que, na realidade, reforça a exclusão, suprime as diferenças de classe, gênero e raça (SOUZA, 2007, p. 54).

A hierarquia social e econômica existente entre homens e mulheres e a sua reprodução no espaço científico, são frutos de inúmeros aspectos históricos de marginalização feminina da esfera pública, dentre os vários é notória a vinculação visual e imagética de cientistas como sendo algo apenas do sexo masculino, resultando na ausência histórica de representatividade feminina no campo das ciências. A partir dos ideários de invisibilidade e silenciamento que são construídos lugares pautados em perspectivas de gênero, é a partir disso que as mulheres tem suas faculdades intelectuais questionadas e colocadas em julgamento todo o tempo.

O relato abaixo das interlocutoras nos exemplifica a proposição supracitada:

No meu curso de física entraram quarenta e cinco pessoas, eram cinco meninas e quarenta meninos. Na primeira aula de laboratório os meninos meio que já excluíam a gente por sermos meninas, não deixava a gente mexer nos equipamentos, não confiava nos cálculos que a gente fazia. Se o professor viesse, explicasse algo que ninguém entendesse, mas eu entendia, eu ia tentar explicar, mas eles não me ouviam. Havia sim um preconceito desde o início, só do meio da graduação para frente, quando já havia dado tempo de eu ter demonstrado que sabia, aí eu comecei a ter voz, então a partir disso eu era ouvida (Docente A, 2018).

Tive uma professora, com formação em Geologia, que comentava sobre suas idas a campo, que ela não tinha nenhuma ajuda dos colegas do curso, ela tinha que agir como um menino, além disso, havia uma concorrência muito grande, ela tinha que fazer alguma diferença para ser reconhecida num curso estritamente masculino (Docente C, 2018).

A docente A retratou que durante suas trajetórias eram perceptíveis as indagações e questionamentos quanto a escolha do curso de Física, por se tratar de um curso na área das ciências exatas, onde há baixa representatividade feminina e a presença de mulheres era quase nula. As acadêmicas tinham que lidar com atitudes sexistas por parte de colegas de classe e professores em relação a possibilidade de conseguirem ou não atender as demandas do curso, pura e exclusivamente por serem mulheres e haver a ideia de que elas apresentam mais tato para outras áreas.

Uma das interlocutoras se apresentavam cientes dessa conjuntura enquanto a outra conseguiu realizar esse processo reflexivo somente enquanto revisitava 
suas trajetórias, note as distinções nas duas falas:

Cheguei a ter problemas com um professor meu, ele não deixava a gente falar então eu percebi que era meio que uma coisa contra as meninas. Ele não nos dava voz e quando a gente reclamava ele dizia que a gente tava de 'mimimi' [sendo exagerada] e dizia coisas do tipo "por isso que eu não gosto de mulher no laboratório" [...] (Docente A, 2018).

Eu nunca havia parado pra pensar sobre isso, que sendo uma área [Geologia e Paleontologia] com predominância de homens que também eram competentes, estes não nos dava espaço para a gente trabalhar da mesma forma (Docente C, 2018).

Uma das interlocutoras retrata que havia pouquíssimas mulheres na graduação e as poucas presentes tiveram muita dificuldade em permanecer, gerando um intenso processo de evasão feminina, demonstrando sobretudo a hostilidade do ambiente acadêmico a figuras femininas que constantemente são repreendidas e psicologicamente induzidas a se retirarem, por acreditar que não podem cumprir as exigências acadêmicas:

Da minha turma, das cinco meninas, só eu consegui terminar o curso. Muitas delas desistiram logo nos primeiros semestres, uma delas foi até mais além, porém não conseguiu concluir. Na UFT temos até bastantes meninas no curso de física, mas naquela época, naquele lugar era muito complicado (Docente A, 2018).

De forma contrária, foram relatados casos de docentes que tiveram suas turmas de graduação com predominância feminina. Sendo importante citar que as docentes reconheciam estar fugindo a regra:

Eu entrei na turma que era de 40 e acabou sendo 42 alunos, a turma em grande parte era feminina, então sim, a turma era em grande parte dominada por mulheres, porém a gente tinha uma boa relação com os meninos, assim como temos até hoje. Nesse caso a relação dos gêneros aconteceu de forma bem bacana eu não sei se era outro tipo de contexto, outras mentalidades, mas a gente percebia que o respeito mútuo dentro da sala era mantido (Docente F, 2018).

Como meu curso é turismo prioritariamente tem muita mulher e na minha realidade os homens que faziam parte em sua grande maioria eram homossexuais. O que já é o inverso do Curso de Economia que eu faço agora, onde a maioria é masculina. Eu também fiz geoprocessamento e na minha sala tinha apenas cinco mulheres no universo de 20 a 25 alunos então percebi que varia muito pela área, pelo Campo de estudo (Docente E, 2018).

O relato da docente E evidencia uma perspectiva aferida no decorrer de seus 
trajetos, expondo questões relacionadas ao sexismo em suas várias escalas, desde a forma mais acentuada até a mais sutil, levando em consideração que a mesma havia frequentado distintas espacialidades na academia.

Dessa forma, compreendemos que determinados campos de estudo carregam um maior peso em relação à intensa masculinização, enquanto outros são marcadas pela presença quase nula, uma concepção totalmente pautada nos papéis de gênero construídos historicamente e socialmente, onde há lugares destinados a atividade feminina e masculina.

Áreas intensamente masculinizadas em seus primórdios, se configuram em espaços que apresentam, até os dias de hoje, resquícios de um sistema androcêntrico e isso pode ser constatado a partir da inserção feminina no ramo das Ciências agrárias, principalmente no mercado de trabalho para médicas veterinárias e zootecnistas.

Docentes do colegiado de Zootecnia e Medicina Veterinária nos trazem relatos sobre seus trajetos:

Em algumas entrevistas para a iniciativa privada passei por momentos de desconforto onde os entrevistadores deixavam bem claro que o emprego ali era para homens, e a conversa realmente não foi muito agradável, pois, eu disse que minha capacidade de gerenciar uma fábrica de ração era igual ou maior do que muitos homens e que eu não via o porquê daquele preconceito conosco. $O$ resultado? Contrataram homens e eu tive que continuar minha caminhada [...] (Docente H, 2018).

A Medicina veterinária é uma profissão que exige muito esforço físico, por exemplo, ter que conter um animal. Essa questão para mulher torna-se muito complicado, uma veterinária que trabalha com bovinos, o tratador olha pra você e diz que você não vai conseguir, fica com aquele olhar: 'é mulher? não vai dar conta!'é uma profissão que ainda é muito masculina dependendo da vertente (Docente J, 2018).

São as identidades de gênero que perpetuam as subdivisões daquilo que é pertinente ao universo masculino e feminino, inferindo que tudo pertencente ao universo das mulheres resulta numa noção de incapacidade e inabilidade, logo somos inseridas desde a infância num contexto distinto dos meninos, não sendo instigadas para áreas tais como ciências exatas, agrárias, construção civil, dentre tantas outras.

De acordo com Mary Drumont, em suas pesquisas sobre elementos para uma análise do machismo:

O machismo enquanto sistema ideológico oferece modelos de identidade tanto para o elemento masculino como para o elemento feminino. Ele é aceito por todos e mediado pela liderança masculina. Ou seja, é através deste modelo normalizante que homem e mulher "tornam-se" homem e mulher, e é também através dele, que se ocultam partes essenciais das relações entre os sexos, invalidando-se 
todos os outros modos de interpretação das situações [...] Desde criança o menino e a menina entram em determinadas relações, que independem de suas vontades, e que formam suas consciências: por exemplo, o sentimento de superioridade do garoto pelo simples fato de ser macho e em contraposição o de inferioridade da menina [...] em termos de trabalho a menina é geralmente conduzida para as atividades que não produzem dinheiro, enquanto que o garoto é necessariamente orientado para uma profissionalização (DRUMONT, 1980, p. 81).

A partir das oralidades das docentes tornou-se evidente as inúmeras situações de machismo sofridas ou presenciadas pelas mesmas no contexto acadêmico-científico. São inúmeros os questionamentos quanto à capacidade cognitiva, intencionalidade profissional, contexto familiar, cuidados com a família, filhos e dedicação ao trabalho que, sem dúvidas, não deixam alternativas que não seja reagir e resistir perante uma estrutura que mitiga a figura feminina.

Uma das interlocutoras quando foi questionada sobre os empecilhos encontrados em seus trajetos e como fez para contorná-los, declarou: "A gente tem que ser forte, não tem outra opção"(Docente B, 2018), apontando o quão forte devem se tornar durante as trajetórias na academia e fora dela.

Segue mais algumas situações de machismo vivenciadas pelas interlocutoras no contexto acadêmico:

Na hora da escolha de equipe de locais de trabalho no estágio eu já presenciei um preceptor que foi escolhendo primeiramente todos os homens, depois que escolheu as meninas, a gente via claramente a preferência [...] Existem locais que só aceitam homens para estágio e eles deixam bem claro que aceitam apenas homens, e isso acontece até hoje (Docente L, 2018).

Eu passei por uma situação muito chata, não foram só uma, foram várias, com um colaborador no meu pós-doutorado. Quando eu comecei a fazer o pós-doutorado eu comecei a trabalhar com esse colaborador, ele era professor na universidade e o tempo todo ele fazia comentários machistas comigo na frente de outras pessoas, eu não sabia muito bem como responder por que ele era meu colaborador e eu não queria que ficasse um clima esquisito, porém eu achava comportamento dele muito machista e até mesmo infantil (Docente M, 2018).

Quando eu via minha orientadora indo para o campo às sete da manhã e retornando as 18 eu pensava no quanto ela era competente, sem falar que ela tinha outras obrigações, era casada, tinha filhos, às vezes precisava se deslocar para outra cidade e ficar vários dias fora de casa, são outras atribuições realizadas por mulheres que muitas das vezes não são desenvolvidas pelo homem, além do trabalho fora de casa, tem o trabalho interno (Docente D, 2018). 
Situações de assédio moral ou mesmo sexual se dispõem nos trajetos relatados. Reduzidas ao aspecto físico e emocional, em detrimento do intelectual, assediadas no ambiente do trabalho por parte de colegas e tendo inclusive que repensar as roupas que utiliza enquanto leciona. Nesse contexto, uma das interlocutoras retrata que:

Antes do meu momento da palestra eu estava com umas folhas olhando o que tinha nos slides que eu ia palestrar porque eu estava nervosa, então ele (professor colaborador do pós-doutorado) chegou próximo de mim, perguntou o que estava acontecendo, eu disse que estava nervosa, ele me disse para não ficar nervosa porque se qualquer coisa acontecesse eu só precisava tirar a roupa lá na frente de todos que as coisas se resolviam, na hora eu fiquei sem reação, me deu vontade de chorar e ele estava ali me olhando com um sorrisinho irônico querendo me dizer que ele não precisou fazer nada disso para chegar onde ele chegou (Docente A, 2018).

Na verdade, o meu grupo do mestrado, eles eram bem predadores, talvez eu nunca tenha passado por alguma situação assim porque eu nunca chamei muita a atenção dos meninos. Mas já presenciei isso acontecendo com duas professoras, eles simplesmente usavam do artificio de trabalhar com fisica para dar cantadas, isso era muito chato, porque teve ocasiões que eu já vi eles comentando na minha frente sobre o corpo delas (Docente K, 2018).

Quando se trata das implicações no âmbito da maternidade e da vida conjugal temos o surgimento de outras configurações. Saber conciliar o convívio no âmbito científico, as cobranças advindas da profissão professora, sobretudo pesquisadora e as jornadas que deixaram de ser duplas e tornaram-se quádruplas.

No que tange as cobranças quanto ao ser mulher, ser mãe, ser esposa e as demais expectativas sociais pertinentes ao gênero, podemos estabelecer alguns diálogos a partir dos relatos:

[...] eu vejo é que a mulher sofre muito com isso ainda, você pode ser uma cientista de ponta ter vários trabalhos, porém sua vida pessoal, a vida pessoal da mulher tem quase que ser deixada de lado, bem dificil conciliar [...] Então a mulher tem essa questão quanto à vida pessoal, de ser esposa, de ter filhos, ela tem que adaptar a sua vida ao do companheiro e não o companheiro a dela, é o que dá pra entender nas entrelinhas [...] (Docente K, 2018).

[...] a gente não deixava de ouvir piadinhas do tipo "porque não vai cuidar dos seus filhos", "porque não deixa essa vida de tá estudando aqui, isso aqui é para quem é jovem!". Isso é desanimador, nós tínhamos um professor de matemática básica I, com discurso bastante machista ele não desistia de falar que não tínhamos competência para ensinar matemática [...] (Docente J, 2018).

Raquel Almeida Mendes, Kenia Gonçalves Costa 
Eu terminei a graduação grávida da minha primeira filha, fiz a especialização grávida do meu segundo filho e dei aula na UNITINS, eu já estava grávida do meu terceiro [...] então eu sempre dava aula, viajando, e grávida, é uma dificuldade muito grande, quando eu penso atrás no que eu fiz, eu nem sei se eu daria conta de repetir [...]' (Docente I, 2018).

Ainda que as lutas pelo desconfinamento da mulher a esfera doméstica tenha gerado avanços consideráveis e aos poucos o público feminino esteja adentrando espaços estritamente masculinizados, é importante ressaltar que no imaginário da sociedade ainda prevalece a figura feminina como sendo a responsável pela conciliação das duas funções no exercício do trabalho remunerado e não-remunerado (atividades domésticas), ou seja, até que ponto a mulher tem alcançado sua liberdade? Nesse caso, nota-se apenas um acréscimo de mais responsabilidades e o fomento a jornadas exaustivas em detrimento de privilégios masculinos.

\section{Considerações finais}

A ressignificação de papéis estruturalmente masculinos na ciência e na academia tem gerado um avanço no que tange o rompimento das identidades de gênero, bem como uma eficaz inserção das mulheres na esfera pública, ou seja, em espaços anteriormente negados. Esse processo é fruto de intensa luta de mulheres em movimento que se viram abraçadas pelas possibilidades de ir além do que foi disposto, proposto e imposto.

Compreendemos que os avanços são necessários a mesma maneira que também entendemos os resquícios de uma sociedade historicamente sexista que não se modifica celeremente.

As mulheres ao percorrerem diferentes trajetos e espaços, têm caminhos sinuosos que acreditamos aos poucos estarem sendo abertos por cada figura feminina insurgente que avança. $\mathrm{O}$ entendimento das trajetórias socioespaciais de mulheres docentes e pesquisadoras na universidade nos aponta isso, nos demonstra que as precursoras das docentes muito sofreram e por vezes precisaram gerir suas feminilidades para se encaixar no espaço acadêmico, algo que as interlocutoras da pesquisa as suas maneiras também fizeram.

A aferição dos trajetos, somada às oralidades, proporcionou uma melhor dimensão das desigualdades de gênero estabelecidas no âmbito científico e de como cada docente, segundo sua área de atuação, enfrenta aspectos peculiares e específicos no cumprimento de suas atividades.

As espacialidades de cada interlocutora, cientes ou não desse processo, tiveram as condicionantes do gênero, do sexismo e do machismo presentes. Ainda que na condição de docentes pesquisadoras, lotadas em uma instituição pública de ensino superior, elas ainda precisam dispor de mecanismos para lidar com fatores tais. 


\section{Referências}

ALVES, Branca Moreira, PITANGUY, Jacqueline. O que é FEMINISMO. São Paulo: Editora Abril cultural: Brasiliense, 1985.

BUTLER, Judith. Fundamentos contingentes: o feminismo e a questão do pósmodernismo. Cadernos Pagu, n. 11, p. 11-42, 1998. Tradução de Pedro Maia Soares para versão do artigo "Contingent Foundations: Feminism and the Question of Postmodernism", no Greater Philadelphia Philosophy Consortium, em setembro de 1990.

CIRQUEIRA, Diogo Marçal. Entre o corpo e a teoria [manuscrito]: a questão étnico-racial na obra e trajetória de Milton Santos. 2010. Dissertação (Mestrado) - Programa de Pós-Graduação em Geografia, UFG, Goiânia - GO.

COLLING, Ana Maria. A construção histórica do feminino e do masculino. In: STREY, Marlene Neves; CABEDA, Sonia T. Lisboa; PREHN, Denise Rodrigues (Orgs.). Gênero e cultura. Questões contemporâneas. Porto Alegre: Edipucrs, 2004, p. $173-198$.

DRUMONT, Mary Pimentel. Elementos para uma análise do machismo. Perspectivas: Revista de Ciências Sociais, v. 3, n. 81 - 85, 1980.

GIOMETTI, Analúcia Bueno dos Reis; PITTON, Sandra Elisa Contri; ORTIGOZA, Silvia Apareci da Guarnieri. Leitura do espaço Geográfico através das categorias: lugar, paisagem e território in: Universidade Estadual Paulista/PROGRAD. Caderno de formação de Professores, Bloco 02 Didática dos Conteúdos, volume 9. São Paulo: Cultura Acadêmica, 2012, p. 33-40.

LOPES, Luciane Gomes. Gênero como Categoria Condicionante de Delimitações Espaciais: Uma Análise da Trajetória Feminina na PósGraduação e Produção do Conhecimento. Revista Latino-americana de Geografia e Gênero, v. 6, p. 154 - 168, 2015.

LOURO, Guacira. Gênero, sexualidade e educação: uma perspectiva pósestruturalista. Petrópolis: Vozes, 1997.

OKIN, Susan. Gênero: O Público e O Privado. Revista Estudos Feministas, v. 16 , p. $305-332,2008$.

RAMIRES, Júlio Cesar de Lima; PESSOA, Vera Lúcia Salazar (org.). Geografia e Pesquisa Qualitativa: nas trilhas da investigação. Uberlândia: Assis, 2009.

REIS, Maíra Lopes. Estudos de Gênero na Geografia: uma análise feminista da produção do espaço. Espaço \& Cultura, v. 38, p. 11 - 24, 2015. 
SAFFIOTI, Heleieth. Gênero, patriarcado e violência. São Paulo: Editora Fundação Perseu Abramo, 2004.

SANTOS, Milton. A Natureza do Espaço: técnica e tempo, razão e emoção. São Paulo: Hucitec, 1997.

SCHIEBINGER, Londa. O feminismo mudou a ciência? São Paulo: EDUSC, 2001.

SILVA, Fabiane Ferreira da. Corpos femininos superfície de inscrição de discursos: mídia, beleza, saúde sexual e reprodutiva, educação escolarizada...2012. Dissertação (Mestrado) - Programa de Pós-Graduação em Educação em Ciências: Química da Vida e Saúde, UFRGS, Porto Alegre RS.

SILVA, J. M; CHIMIN JR, A. B.; PARACETTA FILHO, E.; ROSSI, Rodrigo. Geografia e gênero no Brasil: uma análise da feminização do campo científico. Ateliê Geográfico, v. 3, p. 38 - 62, 2009.

SILVA, Joseli Maria. (Org.). Geografias subversivas. Discursos sobre espaço, gênero e sexualidades. Ponta Grossa /PR: Todapalavra, 2009.

SOUZA, Lorena Francisco de. Corpos Negros Femininos em Movimento: Trajetórias Socioespaciais de Professoras Negras em Escolas Públicas. 2007. Dissertação (Mestrado) - Programa de Pós-graduação em Geografia, UFG, Goiânia - GO.

TRIVIÑOS, Augusto Nibaldo Silva. Introdução à pesquisa em ciências sociais: a pesquisa qualitativa em educação. São Paulo: Atlas, 1987.

UNIVERSIDADE FEDERAL DO TOCANTINS. UFT. Gerência de Desenvolvimento Humano. UFT/Campus Araguaína - TO, 2017.

VELEDA DA SILVA, Susana Maria. A perspectiva feminista na Geografia brasileira. In: Silva, Joseli Maria. (Org.). Geografias subversivas. Ponta Grossa: Todapalavra, 2009, p. $300-313$.

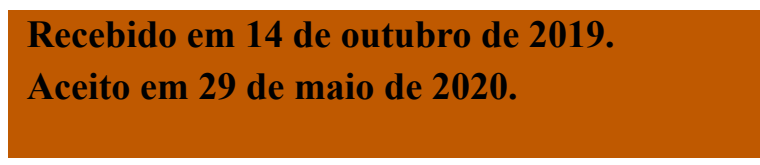

Raquel Almeida Mendes, Kenia Gonçalves Costa 